\title{
Influence of the Menstrual Cycle on Blood Pressure Post Resistance Exercise in Young and Healthy Women
}

\author{
Andrea Solera-Herrera ${ }^{1,}$, ${ }^{\text {Elizabeth Carpio-Rivera }}{ }^{2}$, Julian Camilo Garzon-Mosquera ${ }^{1}$, \\ Rodolfo Obando-Monge ${ }^{3}$ \\ ${ }^{1}$ Human Movement Science Research Center (CIMOHU), University of Costa Rica, San José, Costa Rica \\ ${ }^{2}$ School of Physical Education and Sports, University of Costa Rica, San José, Costa Rica \\ ${ }^{3}$ Departament of Physiology, Medical Sciences University, San José, Costa Rica
}

Email address:

andrea.solera@ucr.ac.cr (A. Solera-Herrera), elizabeth.carpiorivera@ucr.ac.cr (E. Carpio-Rivera), bike_camilo@hotmail.com (J. C. Garzon-Mosquera),jose.obandomonge@gmail.com (R. Obando-Monge)

${ }^{*}$ Corresponding author

\section{To cite this article:}

Andrea Solera-Herrera, Elizabeth Carpio-Rivera, Julian Camilo Garzon-Mosquera, Rodolfo Obando-Monge. Influence of the Menstrual Cycle on Blood Pressure Post Resistance Exercise in Young and Healthy Women. American Journal of Sports Science.

Vol. 7, No. 4, 2019, pp. 164-170. doi: 10.11648/j.ajss.20190704.16

Received: October 1, 2019; Accepted: October 26, 2019; Published: November 6, 2019

\begin{abstract}
To determine if the menstrual cycle phase (menstruation versus late follicular phase) influences in the response of blood pressure (BP) after the resistance training (RT), nineteen university students, young and healthy women (age: 18,6 $6 \pm 1,47$ years old; weight: $55,8 \pm 8,0 \mathrm{~kg}$; height: $157,9 \pm 6,4 \mathrm{~cm}$ ) participated in six RT sessions. Low intensity was for the first three sessions for the subjects to be familiarized with breathing, speed and exercise techniques. In the fourth session, one maximum repetition (1RM) was applied in each resistance exercise. Once this value was determined (RM), the participants applied the RT protocol by $60 \%$ intensity of $1 \mathrm{RM}$, one session during menstruation and another one close to ovulation. The RT protocol included three repetitions per set in 10 exercises. Previous, immediately after and during 24-hours after the RT, the BP was monitored using the ambulatory BP to determine if the RT varied based on the menstrual cycle. The ANOVA demonstrated no significant differences in neither the systolic blood pressure (sBP), diastolic, nor media during 24-hour considering waking or sleeping periods, but the heart rate (HR) values were higher when participants were close to ovulation compared when they were in their period. The observation by hours after the RT demonstrated that: (1) no matter the menstrual cycle period, the systolic BP was higher while the diastolic was lower immediately after the RT, (2) at the beginning of the day; the BP values were lower during the late follicular phase. In conclusion, the hypotension post-RT was not affected by the menstrual cycle although the HR was higher during the late follicular phase.
\end{abstract}

Keywords: Menstrual Cycle, Blood Pressure, Resistance Training, Hypotensive Effect

\section{Introduction}

Presently, the adverse effects of a sedentary lifestyle on people's health are indisputable [1]. Sedentary lifestyle is associated with the development of a diversity of illnesses such as metabolic, pulmonary, heart disease, among others. For this reason, many studies have focused on determining the effects that physical activity has on physiological parameters associated with health.

Based on a study [2], one factor affected in a positive way over BP is exercising. Although many studies are focused on determining the chronic effect of exercising on BP after some weeks or months of training, others have studied the acute effect on BP in the following hours after exercising [3, 4]. This decreasing of BP due to exercise is known as postexercise hypotension (PEH), determined by comparing BP values after exercising with $\mathrm{BP}$ values previous exercising or with the values obtained randomly without exercising $[3,5]$.

In a recent meta-analysis related to the acute effect of exercising on BP [6], it was determined that after exercising BP decreased independently the exercise type practiced or the sample's characteristics. Nonetheless, the fact that only the third part of 1408 participants in the meta-analyzed 
studies were women. That could be interpreted that the obtained conclusions derived from studies with a majority of men as participants [7].

Very likely scientists prefer male samples to females because they probably believe that the menstrual cycle produces an interaction on the PEH due to the hormone variations during its phases [8]. For example, previous ovulation circulating levels of estradiol increase and, during menstruation a significant increase of follicle stimulating hormones (FSH) and luteinizing hormones $(\mathrm{LH})$; concentration that decreases around menstruation approaches [9].

Similarly, one expects that the increase in the estrogen secretion during ovulating could affect on the blood vessels increasing the production of nitric oxide [10], which works as vasodilator substance [11, 12] favoring the BP decreasing after exercising. On the other hand, during the menstruation that potential effect would not be present due to the reduction in the circulated level of estrogen and progesterone.

Importantly, the authors only know about two previous studies in which the hypotensor effect of aerobic exercise was evaluated based on the menstrual cycle [13, 14]. For this reason, the objective of this research is to determine whether the menstrual cycle influences on the hypotension effect of RT in young and healthy women.

\section{Methodology}

\subsection{Participants}

Nineteen normotensive, healthy and fertile women participated in this study, who did not practice more than two hours of RT per week and had at least six months of non-pharmacological or hormone therapy that could affect their menstrual cycle or BP. Table 1 shows the main characteristics of the sample.

\subsection{Procedure and Measurement Instruments}

The Scientific Ethics Committee of the University of Costa Rica approved this study. Volunteers participated in seven different sessions every other week. During the first session, all subjects were informed about the study and signed an informed consent form before the beginning of the study. In addition, some questionnaires were applied to collect some personal information: age, menstrual cycle (duration and characteristic), and exercise habits.

They were instructed to (a) not have illnesses or injuries that could affect the physical performance, (b) not take medicines or hormones that could affect BP and/or the menstrual cycle, among others.

After that, some measures were applied in the Human Movement Science Research Center (CIMOHU by its acronym in Spanish) of the University of Costa Rica:

1. Height: assessment of height used a stadiometer (Novel Products Inc, model PAT-DES 290 237, Rockton, Illinois) with a precision of $0.05 \mathrm{~cm}$.

2. Weight: Tanita scale was used, model HD-313 (Japan), with a precision of $0.01 \mathrm{~kg}$.

3. Body mass index (BMI) was calculated using the formula: $\mathrm{BMI}=\mathrm{kg} / \mathrm{m}^{2}$.

4. Body fat was determined using bone densitometry (DEXA, Lunar Prodigy, General Electric, Madison, Wisconsin).

5. Resting BP was assessed by using an automatic sphygmomanometer (OMRON), model Bp791it.

6. Electrocardiogram was done using a General Electric electrocardiograph Modelo Cam-14 (Finland). A physician interpreted the data to determine whether those participants were able to participate or not in the study.

All the six workouts were done in the Weight Room in the School of Physical Education and Sports at the University of Costa Rica. They had a 5-min warm-up on a stationary bicycle with a little resistance by $60 \%$ of their heart rate reserve (HRR) monitored with HR, Polard, model FT7, (Kempele, Finland).

For the second to fourth sessions, the participants familiarized with the RT. They performed three repetitions per set in 10 exercises with 1-min rest time between sets done in CYBEX equipment: knee extension, neutral paddle traction, knee flexion, inclined bench press, leg press, hip flexion to work abdominal muscles, hip abductor, elbow flexion with pulley, hip abductor and elbow extension. All the exercises were executed in intensity 3, which means easy (OMNI-Resistance Exercise Scale OMNI-RES) [15].

In the workout, they practiced the technique correctly, to keep a 2-s execution tempo for the concentric phase and 2-s execution for the eccentric phase, and to exhale the air during the eccentric phase to avoid the Valsava maneuver as well.

The fifth session was focused on assessing the maximum strength for every of the ten training workouts using the 1RM. After the bicycle warm-up, the 1RM measurement protocol included 10-exercise repetitions using low weight. After that, they were asked to use a determined load. In case the subjects did not get the 1RM o did more than one repetition, she rested the muscles for 5-min and tried again with a lower or higher load depending on the case. In the $1 \mathrm{RM}$, the load that the participant was able to complete in one repetition was considered, keeping the correct technique in both, the concentric or the eccentric exercise phase.

Sixth and seventh sessions were experimental. Both were identical, but one was done when the participant indicated she was menstruating and the other one during or close to the ovulatory phase. For determining the ovulatory phase, the ovulation test strips were used, which are an immunochromatographic test in vitro to determine the qualitative LH in the urine. The pharmaceutical company has described its efficacy in identifying the LH peak in 99\% [16].

During the experimental conditions, the participants attended the Weight Room between 7 a.m. to 10 a.m., according to their schedule availability. First, they rested sitting for 5-min to measure the BP before exercise using ambulatory blood pressure monitor (ABPM), SPACELABs, model 90217 (Washington, USA). After that, the participant had a 5-min warm up in a stationary bicycle with a RE by $60 \%$ in every single 10 workouts, with a 1 -min resting 
between sets and exercises.

Immediately the training finished, the participant sat to assess the BP with the ABPM again. Both assessments (before and after) were done in the no-dominant arm, laid on a flat surface on the same level as the heart, with her back flat against the chair, in silence and with her feet both flat on the floor.

Once the post-exercise measurement was applied, the participant changed their clothes to apply the ABPM in her non-dominant arm. The monitor was scheduled for 24-hours to give automatic readings every 30 -min during the day (from 6 a.m. to 10 p.m.) and every 60-min during the night (from 10 p.m. to 6 a.m.).

After a 24-h assessment, the participant turned off the device and returned it to CIMOHU. In case of having more than $70 \%$ of successful readings, the BP average data were taken from: systolic blood pressure (sBP), diastolic blood pressure (dBP), mean blood pressure (mBP), pulse pressure (PP) and heart rate (HR) in (a) 24-hour; (b) waking period, and (c) resting period; also the values of the SBP and $\mathrm{dBP}$ before exercising, after exercising and every hour once training has ended.

\subsection{Statistical Analysis}

Statistical analysis was performed using the Statistical
Package for the Social Sciences (SPSS Inc. Chicago, Illinois, USA) version 15.0 ; the values of $p<0.05$ were accepted as significant.

Descriptive statistics included mean, standard deviation, minimum and maximum of the variables that characterized the sample from every measurement in every condition.

Inferential statistics applied (a) T'students to analyze possible differences between the average between BP and HR. This data was obtained based on women during menstruation compared with women when ovulating; (b) Two ways Analysis of Variance (ANOVAS) ( 2 conditions $\times$ 26 measures) to determine the interaction between the responses of sBP and $\mathrm{dBP}$ toward exercise, depending on the condition and the moment of the measures. When having significant interactions, simple effects post hoc were applied.

\section{Results}

Table 1 summarizes the descriptive statistics of the characteristics of the sample while Table 2 shows the descriptive statistics and the student $\mathrm{t}$ results from the 24-hr obtained values. It is observed that participants have HR significantly higher when they were close to ovulation.

Tabla 1. Characteristics of the sample $(n=19)$.

\begin{tabular}{llll}
\hline Characteristic & Average \pm SD & Minimum & Maximum \\
\hline Age $(\mathrm{y})$ & $18.60 \pm 1.47$ & 17 & 23 \\
Height $(\mathrm{cm})$ & $157.87 \pm 6.43$ & 145 & 173 \\
Weight $(\mathrm{kg})$ & $55.77 \pm 8.02$ & 40.80 & 69.20 \\
BMI $\left(\mathrm{kg} / \mathrm{m}^{2}\right)$ & $22.36 \pm 2.73$ & 18.55 & 27.79 \\
Total fat \% & $37.22 \pm 6.55$ & 24.40 & 49.0 \\
Resting sBP $(\mathrm{mmHg})$ & $109.42 \pm 7.76$ & 92 & 120 \\
Resting dBP $(\mathrm{mmHg})$ & $66.26 \pm 5.48$ & 57 & 77 \\
Resting HR (beats/min) & $70.11 \pm 10.68$ & 54 & 91 \\
Length MC (days) & $29.0 \pm 2.08$ & 25 & 32 \\
Period length (days) & $4.80 \pm 0.85$ & 4 & 7 \\
Menarche & $12.16 \pm 1.26$ & 10 & 15 \\
\hline
\end{tabular}

Abbreviations: SD: standard deviation; BMI: body mass index; sBP: systolic blood pressured; dBP: diastolic blood pressure; HR resting: heart rate resting, MC: menstrual cycle.

Table 2. Descriptive statistics and results of the T'Students in 24 hours, waking period and sleeping period in the different menstrual phases $(n=19)$

\begin{tabular}{|c|c|c|c|c|c|}
\hline Measurement & Variable & Average \pm SD Menstruation & Average \pm DS LFF & t & $\mathbf{p}$ \\
\hline \multirow{5}{*}{ 24-hour } & sBP & $109.79 \pm 7.77$ & $108.90 \pm 7.23$ & 0.917 & 0.37 \\
\hline & $\mathrm{dBP}$ & $67.58 \pm 4.95$ & $66.74 \pm 5.74$ & 0.972 & 0.34 \\
\hline & $\mathrm{mBP}$ & $82.21 \pm 5.32$ & $81.68 \pm 5.74$ & 0.617 & 0.55 \\
\hline & PP & $42.42 \pm 4.39$ & $42.26 \pm 4.60$ & 0.230 & 0.82 \\
\hline & HR & $77.00 \pm 8.43$ & $81.05 \pm 10.64$ & -2.988 & $0.01 * *$ \\
\hline \multirow{5}{*}{ Waking period } & sBP & $112.63 \pm 8.06$ & $111.58 \pm 7.61$ & 1.087 & 0.29 \\
\hline & $\mathrm{dBP}$ & $69.89 \pm 4.71$ & $69.21 \pm 6.09$ & 0.652 & 0.52 \\
\hline & $\mathrm{mBP}$ & $84.47 \pm 5.37$ & $84.05 \pm 5.95$ & 0.436 & 0.68 \\
\hline & PP & $42.58 \pm 4.81$ & $42.00 \pm 5.10$ & 0.721 & 0.48 \\
\hline & HR & $80.21 \pm 9.47$ & $83.95 \pm 11.18$ & -2.624 & $0.02 *$ \\
\hline \multirow{5}{*}{ Resting period } & sBP & $100.16 \pm 7.55$ & $100.05 \pm 7.31$ & 0.081 & 0.94 \\
\hline & $\mathrm{dBP}$ & $58.79 \pm 6.24$ & $57.21 \pm 6.30$ & 1.679 & 0.11 \\
\hline & $\mathrm{mBP}$ & $73.79 \pm 6.26$ & $72.74 \pm 6.42$ & 0.972 & 0.34 \\
\hline & PP & $41.26 \pm 4.02$ & $43.00 \pm 4.20$ & -2.075 & 0.05 \\
\hline & HR & $66.00 \pm 6.25$ & $70.21 \pm 11.16$ & -1.93 & 0.07 \\
\hline
\end{tabular}

Abbreviations: DS: standard deviation; t: the value of T'Students; $\mathrm{p}$ : significance level; sBP: systolic blood pressure; dBP: diastolic blood pressure, mBP: mean blood pressure, PP: pulse pressure; HR: heart rate; LFF: late follicular phase, *significant for each $\mathrm{p}<0.05$. 
Table 3 presents the descriptive statistics of sBP and $\mathrm{dBP}$ in every condition and moment of measurement while Table 4 shows the results of two-way ANOVA of repetitive measurements for sBP and dBP. Findings were: (a) no main effect of conditions (menstruation vs. late follicular phase); (b) a main strong effect of measures ( $<<0.001)$; (c) significant interactions of conditions by measures for both $\mathrm{sBP}(\mathrm{p}=0.049)$ and $\mathrm{dBP}(\mathrm{p}=0.004)$. Figure 1 shows the interactions of $\mathrm{sBP}$ and $\mathrm{dBP}$.

Table 3. Descriptive statistics of the values of SBP and dBP in every condition and moment of measurement $(n=19)$.

\begin{tabular}{|c|c|c|c|c|}
\hline Measurement & $\begin{array}{l}\text { Average } \pm \text { DS sBP in } \\
\text { menstruation }\end{array}$ & Average \pm DS sBP in LFP & $\begin{array}{l}\text { Average } \pm \mathrm{SD} d B P \text { in } \\
\text { menstruation }\end{array}$ & Average \pm SD dBP in LFP \\
\hline Pre & $113.84 \pm 9.43$ & $110.74 \pm 8.97$ & $72.68 \pm 7.72$ & $71.05 \pm 8.80$ \\
\hline Pos & $119.16 \pm 12.33$ & $121.32 \pm 10.83$ & $66.53 \pm 7.75$ & $67.32 \pm 11.66$ \\
\hline $1 \mathrm{hr}$ & $115.16 \pm 13.50$ & $115.74 \pm 9.43$ & $71.95 \pm 7.50$ & $70.58 \pm 8.31$ \\
\hline $2 \mathrm{hrs}$ & $115.05 \pm 12.13$ & $114.68 \pm 10.56$ & $72.42 \pm 6.44$ & $71.84 \pm 7.85$ \\
\hline $3 \mathrm{hrs}$ & $112.47 \pm 7.47$ & $115.37 \pm 10.08$ & $71.58 \pm 7.11$ & $73.05 \pm 9.07$ \\
\hline $4 \mathrm{hrs}$ & $114.37 \pm 8.86$ & $115.74 \pm 9.15$ & $72.21 \pm 9.22$ & $73.63 \pm 8.38$ \\
\hline $6 \mathrm{hrs}$ & $112.10 \pm 16.56$ & $113.84 \pm 11.46$ & $68.11 \pm 9.49$ & $72.32 \pm 10.84$ \\
\hline $7 \mathrm{hrs}$ & $114.21 \pm 9.55$ & $112.42 \pm 11.01$ & $71.42 \pm 7.60$ & $71.63 \pm 9.83$ \\
\hline $8 \mathrm{hrs}$ & $111.63 \pm 13.17$ & $111.37 \pm 12.30$ & $69.95 \pm 10.64$ & $72.21 \pm 11.56$ \\
\hline $9 \mathrm{hrs}$ & $113.58 \pm 13.22$ & $112.89 \pm 13.15$ & $68.11 \pm 9.30$ & $74.26 \pm 11.60$ \\
\hline $10 \mathrm{hrs}$ & $109.00 \pm 11.14$ & $115.63 \pm 16.87$ & $68.79 \pm 10.35$ & $70.58 \pm 12.26$ \\
\hline $11 \mathrm{hrs}$ & $109.58 \pm 11.44$ & $114.16 \pm 12.90$ & $69.37 \pm 7.79$ & $74.05 \pm 13.31$ \\
\hline $12 \mathrm{hrs}$ & $107.26 \pm 13.83$ & $108.05 \pm 8.79$ & $67.42 \pm 12.67$ & $65.32 \pm 9.19$ \\
\hline $15 \mathrm{hrs}$ & $99.42 \pm 11.90$ & $100.37 \pm 11.56$ & $60.21 \pm 10.63$ & $57.63 \pm 10.65$ \\
\hline $16 \mathrm{hrs}$ & $98.37 \pm 9.87$ & $97.89 \pm 7.38$ & $55.74 \pm 8.26$ & $55.16 \pm 8.71$ \\
\hline $17 \mathrm{hrs}$ & $95.63 \pm 10.12$ & $97.68 \pm 8.44$ & $54.95 \pm 8.83$ & $56.68 \pm 9.42$ \\
\hline $18 \mathrm{hrs}$ & $95.89 \pm 10.97$ & $100.68 \pm 9.06$ & $55.11 \pm 9.61$ & $54.68 \pm 8.00$ \\
\hline $19 \mathrm{hrs}$ & $99.79 \pm 8.73$ & $99.05 \pm 8.57$ & $57.16 \pm 9.46$ & $58.10 \pm 7.54$ \\
\hline $20 \mathrm{hrs}$ & $104.00 \pm 12.15$ & $98.95 \pm 6.66$ & $61.32 \pm 9.54$ & $58.37 \pm 10.77$ \\
\hline $21 \mathrm{hrs}$ & $107.53 \pm 10.61$ & $105.32 \pm 13.88$ & $62.68 \pm 8.60$ & $64.26 \pm 8.76$ \\
\hline $22 \mathrm{hrs}$ & $109.58 \pm 9.99$ & $104.37 \pm 10.62$ & $67.79 \pm 8.48$ & $63.47 \pm 9.48$ \\
\hline $23 \mathrm{hrs}$ & $112.32 \pm 12.51$ & $107.84 \pm 10.44$ & $70.05 \pm 10.13$ & $66.11 \pm 7.87$ \\
\hline $24 \mathrm{hrs}$ & $113.53 \pm 13.97$ & $108.58 \pm 9.79$ & $72.16 \pm 7.68$ & $65.32 \pm 7.13$ \\
\hline
\end{tabular}

Abbreviations: SD: standard deviation; sBP: systolic blood pressure; dBP: diastolic blood pressure; LFP: late follicular phase.

Tabla 4. Results of the 2 ways ANOVAS for systolic and diastolic BP.

\begin{tabular}{llll}
\hline Dependent Variable & Independient Variable & p value & \\
\hline & Conditions (menstrual cycle phase) & 0.64 \\
sBP & Measurements (pre and post interventions) & 0.22 & 18.76 \\
& Interaction (2 conditions x 26 measurements & 1.59 \\
dBP & Conditions (menstrual cycle phase) & 0.049 & 0.46 \\
& Measurements (pre and post interventions) & 0.51 & 20.81 \\
& Interaction (2 conditions x 26 measurements & $<0.001$ & 0.004 \\
\hline
\end{tabular}

Abbreviations: sBP: systolic blood pressure; dBP: diastolic blood pressure.

Abbreviations: BP: blood pressure; sBP: systolic blood pressure; dBP: diastolic blood pressure; ${ }^{1}$ : measurement statistically different from pre-test measurement; *: measurement statically different based on the menstrual cycle; ${ }^{a}$ and ${ }^{b}$ : interval measurement of ${ }^{a}$ is different from interval measurement of ${ }^{b}$ in sBP close ovulation; ${ }^{c}$ and ${ }^{d}$ : interval measurement of ${ }^{c}$ is different from the interval measurement of ${ }^{d}$ in sPB during the menstruation; ${ }^{e}$ and ${ }^{f}$ : interval measurement of ${ }^{\mathrm{e}}$ is different from interval measurement of ${ }^{f}$ in dPB close ovulation; ${ }^{g}$ and ${ }^{\mathrm{h}}$ : interval measurement of ${ }^{\mathrm{g}}$ is different from the interval measurement of ${ }^{\mathrm{h}}$ in $\mathrm{dPB}$ during the menstruation

Based on the post hoc analysis of simple effects, main findings were:
1. During the late follicular phase, sBP at the end of the workout is significantly higher than $\mathrm{SPB}$ before exercising. On the contrary, during the menstruation, the sPB shows an increasing tendency after exercising. However, no statistically significant difference was found.

2. During menstruation, the dBP values significantly decreased after exercising comparing with the previous measure. Nonetheless, although dBP's behavior during the late follicular phase tends to be similar, the values did not show a statistically significant difference.

3. Previous resting, during the last hours of the day, BP values are higher when the woman is close to the ovulatory phase. However, when resting, values are 
lower.

4. At the beginning of the next day, the $\mathrm{dBP}$ is lower when the women are in the fertile period. The dBP is similar, although these values are not statistically significant than values during menstruation.

5. In general terms, the values resulted in significantly higher during the wake period compared to the resting period, no matter the menstrual cycle phase.
Nonetheless, as Figure 1 shows:

1) During the late follicular phase, the dBP's values in the waking period are 12 hours higher than the sleeping period while during the menstruation are in this manner only for 9 hours.

2) Similarly, the dBP's values in the waking period decrease for more ( 7 hours) when the women are ovulating compared to when they are not (5 hours).

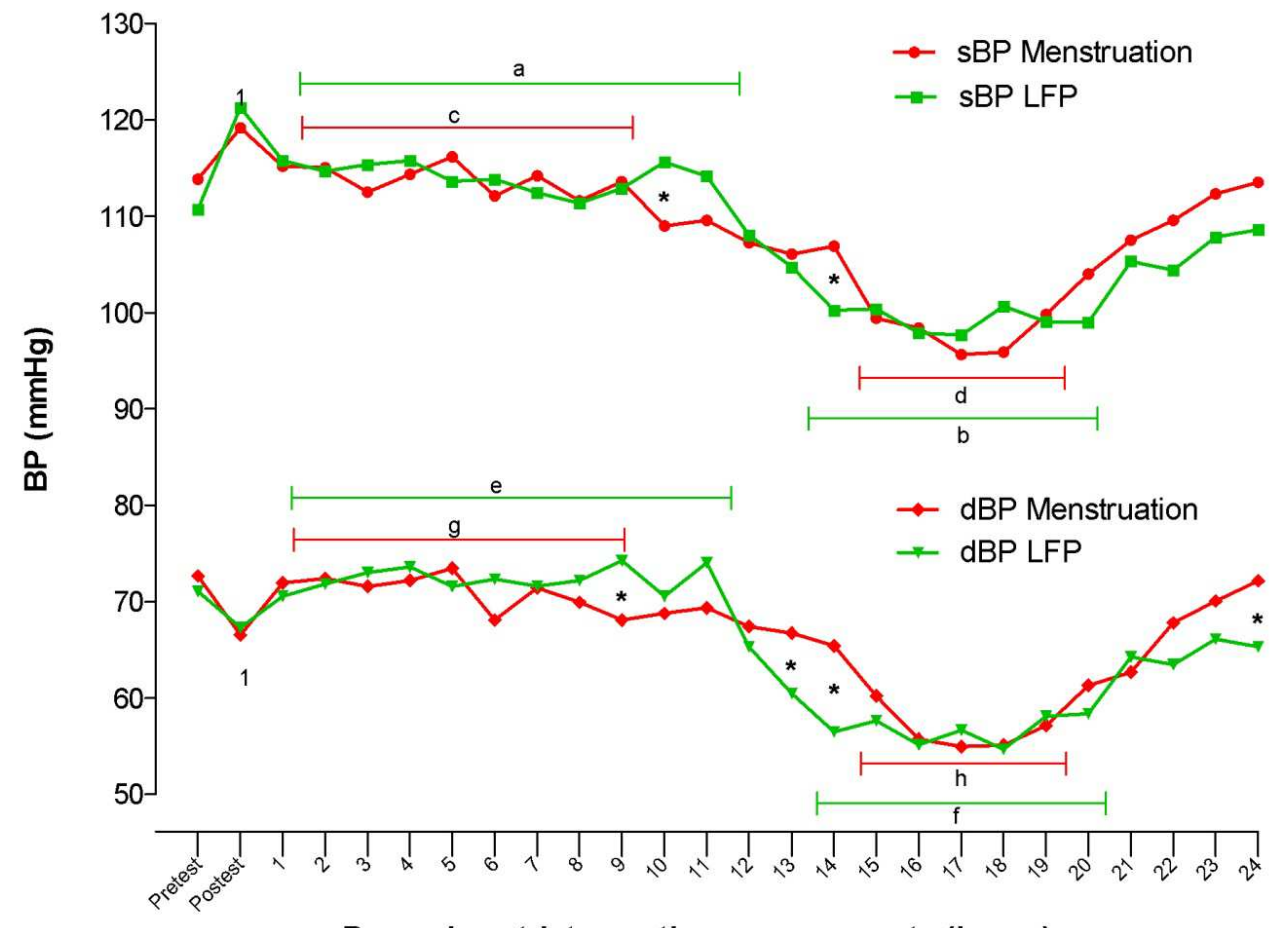

Pre and post-intervention measurements (hours)

Figure 1. Interactions of conditions by measurements in $S B P$ and $d B P$.

Abbreviations: BP: blood pressure; sBP: systolic blood pressure; dBP: diastolic blood pressure; ${ }^{1}$ : measurement statistically different from pre-test measurement; *: measurement statically different based on the menstrual cycle; ${ }^{a}$ and ${ }^{\mathrm{b}}$ : interval measurement of ${ }^{\mathrm{a}}$ is different from interval measurement of ${ }^{\mathrm{b}}$ in sBP close ovulation; ${ }^{c}$ and ${ }^{\mathrm{d}}$ : interval measurement of ${ }^{\mathrm{c}}$ is different from the interval measurement of ${ }^{\mathrm{d}}$ in $\mathrm{sPB}$ during the menstruation; ${ }^{\mathrm{e}}$ and ${ }^{\mathrm{f}}$ : interval measurement of ${ }^{\mathrm{e}}$ is different from interval measurement of ${ }^{\mathrm{f}}$ in $\mathrm{dPB}$ close ovulation; ${ }^{\mathrm{g}}$ and ${ }^{\mathrm{h}}$ : interval measurement of ${ }^{\mathrm{g}}$ is different from the interval measurement of ${ }^{\mathrm{h}}$ in $\mathrm{dPB}$ during the menstruation

\section{Discussion}

Even though this investigation had a strong design to study the postexercise hypotensive effect, because many methodological recommendations were followed, such as having a control condition, realizing pre exercise blood pressure measurements, conducting both experimental conditions the same day of the week and starting the ambulatory blood pressure recording at the same hour of the day [3], no significant difference was found for the hypotensor effect of RT based on the menstrual cycle phase in which the participants were tested (late follicular phase or menstruation).

To the authors' knowledge, only two previous studies have investigated a similar topic to the objective of this study. One was done with eight healthy girls who exercised for 30-min in a stationary bicycle by $80 \%$ of maximum oxygen consumption. Their BP was monitored in the resting period for 45-m after exercising. They found a tendency of having a better hypo-tensor effect of exercising when estrogens were higher [13]. The second study [14] was applied to fourteen women who exercised for 60 -min by $60 \%$ of peak oxygen consume. They observed the BP for 90 -min after exercising and they found that there were no differences in the BP after exercising based on the menstrual cycle.

In this study, 24-hour BP was monitored during the waking period, that is, in their daily lives. The analysis of the 24-hour BP average, including the waking and the sleeping period after the RT session were similar when the participants were close to ovulation comparing with menstruating.

The only parameter that showed significant differences between the two phases of the menstrual cycle was the HR, which was higher close to the ovulatory phase. The difference could be due to women are close to ovulation their body's temperature increase by $0.4^{\circ}[17,18]$ affecting the hypothalamic activity. It is widely accepted that every centigrade degree increases HR by 15 beats/min. That 
explains why HR was about 4 beats/min higher when the participants were menstruating.

The applied monitoring of the behavior of sBP and dBP by hours demonstrated that there are significant differences in a double way. First, in the behavior of BP immediately after the RT due to no matter if they are ovulating or menstruating, the sBP increased and the dBP decreased. This behavior agreed with the results of a study done with men of 38 years old, who did RT one day by $50 \%$ and another day by $70 \%$ of intensity. Then, their BP was monitored one hour after exercising. They found that in the first minutes after RT the sBP increased and the $\mathrm{dBP}$ decreased no matter the intensity [19].

One explanation could be that SBP increase is determined by the HR and the systolic volume [20]. Due to both increases by exercising, it is normal that $\mathrm{sBP}$ increases immediately when exercise ends. In regards $\mathrm{dBP}$, its main determiner is the total peripheral resistance (TPR), which can decrease after concluding exercising due to the reduction in the sympathetic tone and an increasing in liberating vasodilator substances such as histamine and nitric oxide [2, 21].

The other study was focused on the behavior of sBP and $\mathrm{dBp}$ by hours. This one demonstrated BP falls and raises in different moments of the day. The reduction occurred when the person goes to rest is considered normal and it is provoked by the decreasing of sympathetic activity during the night while the lack of this phenomenon might indicate problems of secondary hypertension [22]. It is highlighted that during the menstruation, the decreasing in BP starts 9hours after exercising ends while close ovulation this phenomenon occurs after 13-hours. This could be explained due to two limitations: (1) the difference in the schedule of participants in both conditions, which shorted the period between exercising training and the resting hour during the menstruation than close ovulating and (2) the difficulty in controlling the schedule of sleeping time from 10 p.m. and the waking time at 6 a.m.

The authors suggest this occurred due to small variations in different moments during day hours between BP when they were menstruating compare with close to ovulating. Nonetheless, the average of BP measures of 24-h from the waking and resting period did not show significant differences.

Further studies should better control the schedule of exercising, waking and sleeping periods, and examine different age groups as well. The present study has the limitation of focusing only on young, healthy, and normotensive women. Future studies should consider parameters such as heart rate variability and levels of vasodilator metabolites.

\section{Conclusion}

In summary, the menstrual cycle does not affect hypotension post-RT. For this reason, anyone can investigate the hypotension effect of RT in young, healthy, normotensive women knowing that the menstrual cycle will not interfere in the results.

\section{References}

[1] Lee, S. K., et al., Endothelial nitric oxide synthase activation contributes to post-exercise hypotension in spontaneously hypertensive rats. Biochemical and biophysical research communications, 2009. 382 (4): p. 711-714.

[2] Hamer, M., The anti-hypertensive effects of exercise. Sports medicine, 2006. 36 (2): p. 109-116.

[3] de Brito, L. C., et al., Recommendations in Post-Exercise Hypotension: Concerns, Best Practices and Interpretation. International journal of sports medicine, 2019. 40 (08): p. 487-497.

[4] Casonatto, J., et al., The blood pressure-lowering effect of a single bout of resistance exercise: A systematic review and meta-analysis of randomised controlled trials. European journal of preventive cardiology, 2016. 23 (16): p. 1700-1714.

[5] Cardoso Jr, C. G., et al., Acute and chronic effects of aerobic and resistance exercise on ambulatory blood pressure. Clinics, 2010. 65 (3): p. 317-325.

[6] Carpio-Rivera, E., et al., Acute Effects of Exercise on Blood Pressure: A Meta-Analytic Investigation. Arquivos Brasileiros de Cardiologia 2016. 106 (5): p. 422-433.

[7] Limberg, J. K., et al., $\alpha$-Adrenergic control of blood flow during exercise: effect of sex and menstrual phase. Journal of Applied Physiology, 2010. 109 (5): p. 1360-1368.

[8] Fehring, R. J., M. Schneider, and K. Raviele, Variability in the phases of the menstrual cycle. Journal of Obstetric, Gynecologic, \& Neonatal Nursing, 2006. 35 (3): p. 376-384.

[9] Merz, C. J. and O. T. Wolf, Stress and emotional learning in humans: Evidence for sex differences, in Sex differences in the central nervous system2016, Elsevier. p. 149-170.

[10] Queiroz, A., et al., Gender influence on post-resistance exercise hypotension and hemodynamics. International journal of sports medicine, 2013. 34 (11): p. 939-944.

[11] Lomelí, C., et al., Hipertensión arterial sistémica en la mujer. Archivos de cardiología de México, 2008. 78: p. 98-103.

[12] MacDonald, J. R., Potential causes, mechanisms, and implications of post exercise hypotension. Journal of human hypertension, 2002. 16 (4): p. 225-236.

[13] Esformes, J. I., et al., The influence of menstrual cycle phase upon postexercise hypotension. Medicine and science in sports and exercise, 2006. 38 (3): p. 484-491.

[14] Lynn, B. M., J. L. McCord, and J. R. Halliwill, Effects of the menstrual cycle and sex on postexercise hemodynamics. American Journal of Physiology-Regulatory, Integrative and Comparative Physiology, 2007. 292 (3): p. R1260-R1270.

[15] Lagally, K. M. and R. J. Robertson, Construct validity of the OMNI resistance exercise scale. The Journal of Strength \& Conditioning Research, 2006. 20 (2): p. 252-256.

[16] Wondfo-Biotech, Prueba de ovulación en orina en un solo paso $\mathrm{N}^{\mathrm{o}}$ de cat. W2-S. Retrieved from http://www.wondfousa.com/pro.asp?id=102., 2014. 
[17] Guinart Zayas, N. and J. L. López Leyva, ¿ Qué sabemos de la fiebre. Revista Cubana de Medicina General Integral, 1997. 13 (2): p. 159-165.

[18] Datson, N., et al., Applied physiology of female soccer: an update. Sports medicine, 2014. 44 (9): p. 1225-1240.

[19] Gamboa-Granados, M. and A. Solera-Herrera, Efecto agudo de dos intensidades de ejercicio contra resistencia sobre la presión arterial en reposo de personas normotensas. Pensar en Movimiento: Revista de Ciencias del Ejercicio y la Salud, 2017. 15 (2): p. 1.
[20] Fiedler-Velásquez, E. and C. Gourzong-Taylor, Epidemiología y patogenia de la hipertensión arterial esencial, rol de angiotensina II, óxido nítrico y endotelina. Acta Médica Costarricense, 2005. 47 (3): p. 109-117.

[21] Halliwill, J. R., et al., Postexercise hypotension and sustained postexercise vasodilatation: what happens after we exercise? Experimental physiology, 2013.98 (1): p. 7-18.

[22] Fagard, R. H., Dipping pattern of nocturnal blood pressure in patients with hypertension. Expert review of cardiovascular therapy, 2009. 7 (6): p. 599-605. 